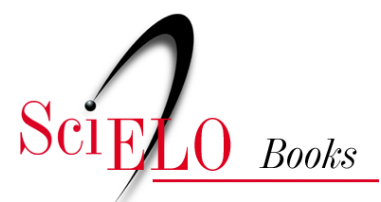

\title{
19. O Falso Caminho das Tiflites e Peritiflites
}

\author{
Joffre Marcondes de Rezende
}

\section{SciELO Books / SciELO Livros / SciELO Libros}

REZENDE, J. M. O Falso Caminho das Tiflites e Peritiflites. In: À sombra do plátano: crônicas de história da medicina [online]. São Paulo: Editora Unifesp, 2009, pp. 173-179. História da Medicina series, vol. 2. ISBN 978-85-61673-63-5. https://doi.org/10.7476/9788561673635.0020.

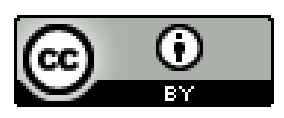

All the contents of this work, except where otherwise noted, is licensed under a Creative Commons Attribution 4.0 International license.

Todo o conteúdo deste trabalho, exceto quando houver ressalva, é publicado sob a licença Creative Commons Atribição 4.0.

Todo el contenido de esta obra, excepto donde se indique lo contrario, está bajo licencia de la licencia Creative Commons Reconocimento 4.0. 


\title{
O Falso Caminho das Tiflites e Peritiflites*
}

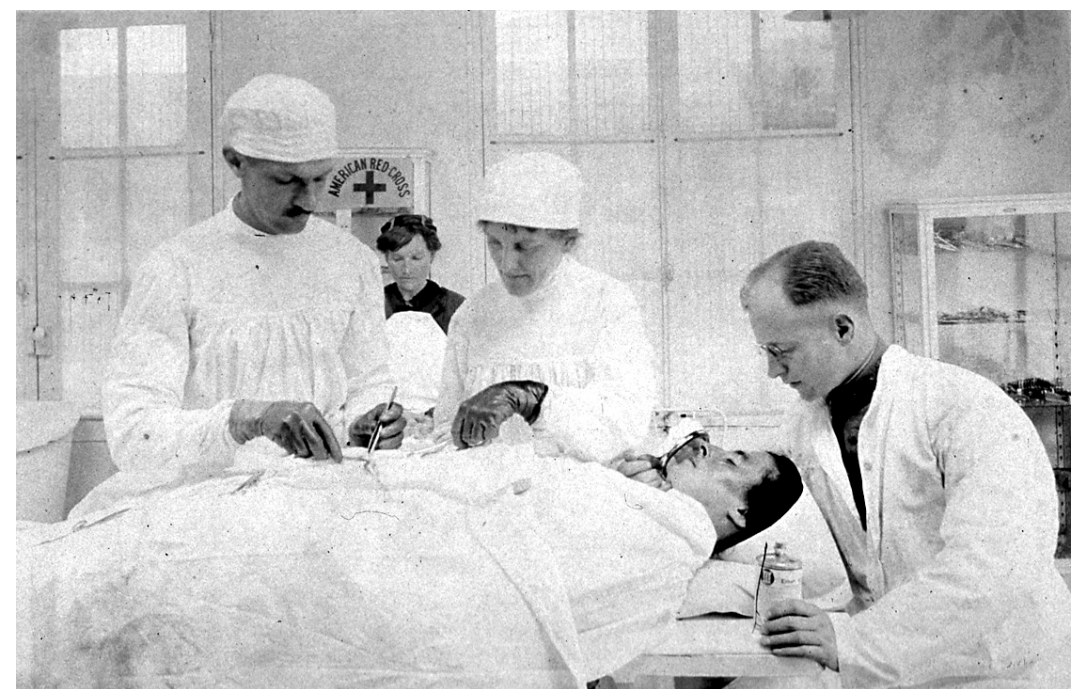

Operação de apendicite, no Hospital da Cruz Vermelha, França, c. I940.

\begin{abstract}
A
história da medicina está repleta de falsos caminhos, que são trilhados durante décadas, ou mesmo séculos, até que o tempo, a experiência acumulada, as novas ideias e as novas descobertas indiquem outra direção a tomar. A mudança de rumo não é fácil. Há uma inércia generalizada e uma acomodação ao pré-estabelecido que se opõem a qualquer ideia inovadora. Exemplo típico é o das tiflites e peritiflites.

Desde a Antiguidade que se conhecem casos de dor abdominal, com reação peritonial localizada na fossa ilíaca direita, náuseas, vômitos e febre.

Antes da descoberta da anestesia geral em I846 e da antissepsia em I 867, a intervenção cirúrgica na cavidade abdominal era uma ousadia e os cirurgiões que se aventuravam a praticá-la sabiam que, além de aumentar o sofrimento do paciente, teriam uma alta mortalidade por peritonite e septicemia. Equivalia quase a um homicídio deliberado.
\end{abstract}

* Publicado na revista Elofar Vida, I, pp. I I-I3, 2005. 
O quadro clínico da peritiflite poderia evoluir de três maneiras: regressão dos sintomas, formação de abscesso que aflorava na parede abdominal, permitindo sua drenagem, ou, o que era mais comum, evoluir para o óbito. Milhares de pessoas em todos os tempos e em todas as latitudes sucumbiram a esta misteriosa doença cuja verdadeira causa era desconhecida. Os que aparentemente se curavam estavam sujeitos a recidivas futuras.

Para explicar as supurações da fossa ilíaca direita, a primeira ideia era de que o processo se iniciasse no ceco, espalhando-se em torno do mesmo, levando à formação de uma tumoração palpável, de consistência firme, que poderia evoluir para abscesso. Este poderia ser esvaziado com uma pequena incisão na parede abdominal e colocação de um dreno.

A afecção deveria receber uma denominação de cunho científico e, como a terminologia médica é essencialmente baseada na língua grega, a inflamação do ceco passou a ser designada por tiflite (do grego typhlós, ceco + sufixo ite, designativo de inflamação) e sua extensão às partes vizinhas, de peritiflite (do grego peri, em torno + typhlós, ceco + sufixo ite). Tais termos foram criados no século XIX (Oxford English Dictionary, I978; Dauzat, Dubois e Mitterrand, I994).

O termo peritiflite se deve a Puchelt e Goldberck, na Alemanha, pois estavam eles convencidos de que a inflamação fosse primariamente do ceco, daí se espalhando às imediações e atingindo o apêndice vermiforme (Thorwald, s.d., pp. 3I 5-348).

Dupuytren, renomado cirurgião francês, atribuía a inflamação à estase fecal no ceco e à presença da válvula ileocecal, um estreitamento que propiciava o aparecimento de secreções e inflamação. $\mathrm{Na}$ época, a supremacia da medicina francesa favoreceu a aceitação desta teoria patogênica por outros centros médicos, como se a mesma tivesse sido comprovada (Idem).

No Dicionário de Medicina Popular, de Chernoviz, todo ele baseado na medicina francesa, encontramos a seguinte definição de tiflite: "Afecção caracterizada pela inflamação de uma parte do grosso intestino que se acha na fossa ilíaca direita, que se chama intestino cego. N'esse lugar as matérias fecaes ficam paradas mais tempo que em outra qualquer parte do tubo digestivo. Sob a influência de prolongada acumulação ou da presença de corpos estranhos irritantes fica inflamado" (Chernoviz, I890). 
Os conhecimentos anatomopatológicos adquiridos até então sobre a tiflite e peritiflite provinham de achados de necrópsia e retratavam o processo inflamatório em sua fase terminal (Morton, I983, pp. 480-482). Não se conhecia a fase inicial nem o local de origem da inflamação. O comprometimento do apêndice era considerado secundário, decorrente da peritiflite.

Todavia, nas autópsias realizadas, chamava a atenção a natureza das lesões apendiculares. $\mathrm{O}$ apêndice achava-se quase sempre contendo pus, roto, esfacelado, ou enegrecido.

Heister, na Alemanha, em I 7 I I, ao autopsiar o cadáver de um criminoso que havia sido enforcado, encontrou o apêndice necrosado e cheio de pus (Thorwald, op. cit.).Relatou o caso, que foi simplesmente ignorado pelos médicos da época. Na Inglaterra, em I 8 I 2, John Parkinson relatou um caso de necrópsia, no qual o apêndice estava inflamado (Parkinson, I 8 I 2, pp. 5758) e, na França, em I 824, Louyer-Villermay autopsiou dois casos fatais de peritonite, nos quais encontrou perfuração do apêndice (Louyer-Villermay, I 824 , pp. 246-250).

O primeiro autor a sugerir a possível relação entre a inflamação do apêndice e os abscessos da fossa ilíaca direita foi o médico francês François Melier, em I 827 (Melier, I 827, pp. 317-343).

O tratamento recomendado para as tiflites e peritiflites consistia em purgativos na fase inicial, "para eliminar as secreções”, e ópio, em caso de agravamento dos sintomas, "para aliviar a dor e colocar o intestino em repouso". Diante dos sinais de formação de abscesso usava-se ainda cataplasma sobre a parede abdominal (Thorwald, op. cit.).

O tratamento cirúrgico com abertura da cavidade abdominal foi realizado com êxito pela primeira vez em I 848, no Charing Cross Hospital, de Londres, por Hancock, em um caso com peritonite e abscesso apendicular. O paciente sobreviveu (Hancock, I 848, pp. 547-550).

Nos Estados Unidos, alguns cirurgiões mais jovens, com ideias inovadoras, passaram a questionar a validade do tratamento clínico conservador nas peritiflites e, apesar da resistência oferecida pela maioria dos médicos, optaram pelo tratamento cirúrgico, que se tornara mais facilmente exequível após a anestesia e a antissepsia. Em I 880, Sands publicava 26 casos operados com apenas dois óbitos. Convencido do acerto de sua conduta preconizou a intervenção precoce com a retirada do apêndice (Sands, I880, pp. 249-270). 
A contribuição decisiva para colocar uma pá de cal na tiflite e peritiflite como entidade nosológica, se deve a Reginald Heber Fitz.

Fitz graduou-se em medicina em I 843, em Harvard, e durante dois anos estudou com Rokytansky, em Viena, e Virchow, em Berlim. Em I 879 foi nomeado professor de Anatomia Patológica na Universidade de Harvard. Demonstrando interesse pela Clínica, tornou-se professor de Medicina Interna a partir de I 892, ocupando esta posição até I908, quando se aposentou (Major, I954).

Em I 886 apresentou à Association of American Physicians seu clássico trabalho no qual relata 25 casos bem documentados de autópsia, mostrando que o processo inflamatório nas peritiflites tem origem no apêndice perfurado. Fitz cunhou o termo "apendicite", que iria suceder aos de tiflite e peritiflite (Fitz, I886, pp. I07-I I4).

De início, sua teoria de que todos os casos de abscesso da fossa ilíaca direita fossem resultantes de apendicite aguda não foi bem recebida, especialmente nos países europeus, onde sequer se admitia o neologismo por ele criado.

Thomas Morton, filho do descobridor da anestesia geral, havia perdido um irmão e um filho de apendicite. Em I 887, um ano após a conferência de Fitz, ele diagnosticou e operou com êxito um caso de apendicite aguda supurada. Este caso foi relatado por Woodbury (Woodbury, I 887, pp. I83). No ano seguinte operou outro paciente em que o apêndice encontrava-se inflamado, mas não havia pus, nem perfuração. Este foi, talvez, o primeiro caso de remoção do apêndice ainda íntegro na apendicite aguda (Thorwald, op. cit.).

Dois cirurgiões norte-americanos, que deram crédito a Fitz, tiveram um papel relevante na comprovação de que o apêndice, e não o ceco, era realmente o local de origem da peritiflite, que poderia ser evitada com a apendicectomia assim que o paciente apresentasse os primeiros sintomas da enfermidade. Foram eles Charles Mc Burney, de Nova York, e John Murphy, de Chicago.

Mc Burney, em i 889, relatou sete casos por ele operados, com apenas um insucesso. Demonstrou que era possível o diagnóstico precoce da apendicite pela palpação do abdome e descreveu o ponto doloroso à pressão digital, hoje conhecido como "ponto de Mc Burney" (Mc Burney, I889, pp. 575-684). 
Murphy foi um entusiasta da apendicectomia precoce, chegando a ter a maior casuística da época. Em I 889 comunicou à Sociedade Médica de Chicago sua experiência de cerca de cem casos operados com êxito. Sua comunicação foi mal recebida e sua conduta foi considerada de um "radicalismo fanático" (Thorwald, op. cit.).

Murphy responsabilizou os clínicos que faziam o primeiro atendimento ao doente pelos maus resultados das operações, decorrentes da demora na indicação do tratamento cirúrgico, agravando o prognóstico. A polêmica ultrapassou o meio médico e alcançou a população leiga. Doentes com sintomas de provável apendicite passaram a exigir o parecer de um cirurgião (Idem).

Aos poucos, a prática da apendicectomia precoce, antes da formação de abscesso, estendeu-se a outros centros médicos norte-americanos.

Na Europa, porém, tanto os clínicos como os cirurgiões persistiam na conduta de iniciar o tratamento com purgativos e ópio, aguardar a evolução e só operar após os sinais de peritiflite com formação de abscesso. Alguns cirurgiões admitiam, no máximo, intervir cirurgicamente antes que o abscesso emergisse na parede abdominal.

Um médico brasileiro, de nome Malaquias Antonio Gonçalves, que estagiou nos hospitais de Paris no final do século xIx, anotou em um diário todas as operações a que assistiu. Dentre elas cita um caso de abscesso por peritiflite operado por Péan, um dos mais ilustres e respeitados cirurgiões da França. Reproduzimos a seguir o texto original tal como se encontra em seu Diário:

Paris, 2I.I I.I89 - Hospital São Luiz - Serviço do prof. Péan - Incisão de um abscesso da fossa ilíaca interna. Dr. Pean narra a história deste doente e passa a praticar a incisão. O dr. Pean é partidário da incisão precoce com o fim de evitar os sérios perigos que correm os doentes sofrendo de abscessos ligados à peritiflite. O dr. Péan incisa camada por camada até o peritônio alguns centímetros acima da arcada de Poupart. Saíu grande quantidade de pus fétido. O dr. Péan introduz um tubo de drenagem e faz uma lavagem antisséptica (Rezende e Freitas, 200I).

Thorwald, em seu livro O Século dos Cirurgiões narra com detalhes os acontecimentos dramáticos que cercaram a coroação do rei da Inglaterra, 
Eduardo viI, filho da rainha Vitória, em decorrência da apendicite aguda que acometera Sua Majestade.

Os fatos se passaram em I902, portanto dezesseis anos após a divulgação do trabalho de Fitz e quando a apendicectomia já era amplamente praticada nos Estados Unidos imediatamente após o diagnóstico de apendicite. Assistido pelos mais famosos médicos de Londres, dentre os quais Lister, o futuro rei teve de esperar nada menos de dez dias antes que se decidisse pela intervenção cirúrgica (Thorwald, op. cit.).

Com o decorrer do tempo, a verdade se impôs e os centros médicos europeus passaram a adotar a conduta da intervenção precoce e abandonaram as denominações de tiflite e peritiflite pela de apendicite.

\section{Referências Bibliográficas}

Chernoviz, P. L. N. Dicionário de Medicina Popular, 6ª ed. Paris, I890.

Dauzat, A. Dubois, J. \& Mitterrand, H. I. Nouveau dictionnaire étymologique et historique, $3^{\underline{a}}$ ed. Paris, Larousse, I994.

Fitz, R. H. "Perforating Inflammation of the Vermiform Appendix: With Special

Reference to Its Early Diagnosis and Treatment". Transactions of the Association of American Physicians, I, pp. I07-I44, I 886.

Hancock, H. "Disease of the Appendix Caeci Cured by Operation". The London Medical Gazette, 7, pp. 547-550, I848.

Louyer-Villermay, J. B. “Observations pour servir à l'histoire des inflammations de

l'appendice du caecum”. Archives of General Medicine, 8, pp. 246-250, I 824.

Major, R. H. A History of Medicine. Oxford, Blackwell Scientific Publications, I954.

Mc Burney, C. "Experience with early Operative Interference in Cases of Disease of the

Vermiform Appendix". New York Medical Journal, 50, pp. 575-684, I889.

Melier, F. "Mémoire e observation sur quesques maladies de l'appendice cécale". Journal of General Medicine, Ioo, pp. 317-343, I827.

Morton, L. T. A Medical Bibliography (Garrison and Morton). London, Gower, I 983. Oxford English Dictionary (Shorter), $3^{\text {a }}$ ed. Oxford, Claredon Press, i978.

Parkinson, J. W. K. "Case of Diseased Appendix Vermiform”. Medico-Chirurgical Transactions, 3, pp. 57-58, I8I2.

Rezende, J. M. de \& Freitas, L. C. B. F. “A Cirurgia no Final do Século xix segundo o Diário do dr. Malaquias Antonio Gonçalves”. vi Congresso Brasileiro de História 
da Medicina. Barbacena, MG, I4-I 7 jun. 200I. Disponível em http://usuarios.cultura.com.br/jmrezende, acesso em 27 ago. 2009.

Sands, H. B. "On Perityphlitis". Annals of the Anatomical and Surgical Society, 2, pp. 249-270, I 880 .

Thorwald, J. O Século dos Cirurgiões. São Paulo, Boa Leitura Editora, s.d.

Woodbury, F. "Cases of Exploratory Laparotomy Followed by Appropriate Remedial Operation", Transactions of the College of Physicians of Philadelphia, 9, pp. I 83, I 887 . 
